\title{
COVID-19 E A SALA DE AULA: UMA COMPARAÇÃO COM A GRIPE ESPANHOLA A PARTIR DA HISTÓRIA EM QUADRINHOS LA DANSARINA
}

\author{
COVID-19 AND THE CLASSROOM: A COMPARISON WITH THE SPANISH FLU FROM LA \\ DANSARINA GRAPHIC NOVEL
}

\author{
COVID-19 Y EL AULA: UNA COMPARACIÓN CON LA GRIPE ESPAÑOLA A PARTIR DE LA \\ HISTORIETA LA DANZARINA
}

\author{
Rodrigo Otávio dos Santos \\ Doutor em História - UFPR. Pesquisador da Fundação Wilson Picler de Amparo à Educação, Ciência e \\ Tecnologia - FAMPECT. Professor do Programa de Pós-Graduação em Educação \\ e Novas Tecnologias (PPGENT), UNINTER, Curitiba, PR, Brasil. \\ ORCID: http://orcid.org/0000-0001-5050-1637 \\ E-mail: rodrigoscama@gmail.com \\ Ingrid Gayer \\ Mestrado Profissional em Educação e Novas Tecnologias - UNINTER. \\ Atuação: Professora do Colégio Sant'Ana / Ponta Grossa \\ ORCID: https://orcid.org/0000-0001-7589-4625 \\ E-mail: ingridgayerp@gmail.com
}

\begin{abstract}
RESUMO
O presente artigo busca contribuir para a questão da pandemia de COVID-19, com relação à conscientização dos estudantes sobre a doença e suas formas de transmissão. O principal objetivo da pesquisa, por meio da história em quadrinhos La Dansarina, é promover um maior entendimento sobre a pandemia, por intermédio da comparação com a Gripe Espanhola. Espera-se, dessa maneira, que os alunos acatem as decisões dos órgãos de saúde e levem adiante tais ensinamentos. A metodologia utilizada no estudo foi a revisão bibliográfica. Como resultado principal, verificou-se que essa comparação entre as duas pandemias - através de obras artísticas — pode motivar e despertar a curiosidade dos alunos, por conta de seus vieses lúdicos. Como conclusões, destacamos que a informação pode ser a maior arma no combate a uma doença que se espalha pelo convívio social e que uma história bem contada pode ser mais útil do que números do noticiário.
\end{abstract}

Palavras-chave: Educação; Covid-19; Formação de professores; História em quadrinhos; Educomunicação.

\section{ABSTRACT}

This article seeks to make a brief contribution to the COVID-19 pandemic issue, regarding the students' awareness of the disease and its forms of transmission. The main objective, through the comic book La Dansarina, is to promote a better understanding of the pandemic, by means of the comparison with the Spanish Flu. Thus, it is expected to make students accept the decisions of the health agencies and carry out such teachings. The methodology used in the study was bibliographic. As a main result, it was verified that a comparison between the two pandemics - through an artistic work - can motivate and arouse students' due to their ludic bias. As conclusions, we can highlight that information can be the greatest weapon in the fight against a disease that spreads through social life and a welltold story can be more useful than news' numbers. 
Keywords: Education; Covid-19; Teacher training; Comics. Educommunication.

\section{RESUMEN}

Este artículo busca hacer una breve contribución al tema de la pandemia COVID-19 con respecto a los estudiantes, su conocimiento sobre la enfermedad y sus formas de transmisión. El objetivo principal es, a través del cómic La Danzarina, promover una mejor comprensión de la pandemia a través de su comparación con la gripe española. Se espera, de esa manera, hacer que los estudiantes sigan las orientaciones de las organizaciones de salud y que pongan en práctica tales enseñanzas. La metodología utilizada en el estudio fue la revisión bibliográfica. Como resultado principal, se pudo verificar que esa comparación entre las dos pandemias - a través de una obra artística —, puede motivar y despertar la curiosidad de los estudiantes debido a su fondo lúdico. Como conclusiones, podemos resaltar que la información puede ser la mejor arma en la lucha contra una enfermedad que se propaga a través de la convivencia social y que una historia bien contada puede ser más útil que los números de los noticieros.

Palabras-clave: Educación; COVID-19; Formación de profesores; Cómics; Educomunicación.

\section{INTRODUÇÃO}

O presente artigo trata de um tema muito presente na atualidade, a pandemia da doença COVID-19 - produzida por um vírus da família dos coronavírus. De acordo com Fiocruz (2020), o nome da doença é derivada do termo Doença do Coronavírus (em inglês COrona Vlrus Disease) somado ao número 19, últimos algarismos do ano em que a doença foi descoberta. Como já divulgado, a maior forma de prevenção da doença é por meio do isolamento social e da higiene simples; entretanto, essas duas formas de prevenção são amplamente difundidas por meio da educação. É preciso, dessa forma, educar as pessoas para que a doença deixe de ser propagada.

Nossa pretensão com este artigo é ajudar na educação de jovens e adultos por meio da história em quadrinhos La Dansarina — produzida por Lilo Parra e Jefferson Costa (PARRA e COSTA, 2017).

\section{Histórias em Quadrinhos}

As histórias em quadrinhos, de acordo com Gordon (1988), surgem com Rudolphe Töpffer em 1833. Elas já tinham como função primária transmitir algum tipo de conhecimento, já que Töpffer era pedagogo e imaginou essa ferramenta como forma de contribuir com a aprendizagem dos estudantes. A história demonstra, 
através de diversos exemplos, que as histórias em quadrinhos foram diversas vezes usadas com a função de dispositivo didático (BRUNER, 2008).

A primeira revista de histórias em quadrinhos brasileira chamada O Tico-tico de 1905, por exemplo, já considerava o caráter didático dos quadrinhos (VERGUEIRO, 2005). Similarmente, podemos afirmar o mesmo dos quadrinhos da extinta editora Ebal (JUNIOR, 2004); Durante o período compreendido entre 1950 e 1980, a editora produzia histórias em quadrinhos com o intuito de transmitir algum conhecimento. Atualmente, existem no Brasil inúmeras histórias em quadrinhos com o intuito específico de ensinar, como os trabalhos realizados pela equipe dos Estúdios Mauricio de Sousa e pelo cartunista Ziraldo. Há, também, editoras que buscam a realização de trabalhos educativos por meio das histórias em quadrinhos, através de adaptações didáticas de clássicos da literatura ou histórias em quadrinhos com o objetivo específico de ensinar uma língua estrangeira.

Eisner (2010) explicita que a função didática das histórias em quadrinhos é uma das principais fontes de informação dos indivíduos, pois, segundo o autor, quadrinhos não são apenas uma junção entre texto e imagem - é algo superior a isso. De acordo com Santos (2016), histórias em quadrinhos são uma linguagem autônoma; assim, elas se relacionam de forma única com seu fruidor, através da sua sintaxe e gramática. As histórias em quadrinhos, como nos conta Groensteen (2015), possuem tantas variações e tantas peculiaridades que o único traço comum a todas é a chamada solidariedade icônica; ou seja, imagens que participam de uma sequência ainda que estejam separadas por alguma espécie de divisão. Entretanto, outras manifestações artísticas também possuem essa característica - como a conhecida Tapeçaria de Bayeux ou os hieróglifos egípcios - e não são consideradas histórias em quadrinhos. Portanto, voltando à Gordon (1988), é necessário incluir mais um elemento na classificação, que é a reprodução em massa.

Essa característica, de mídia de massa, também interessa à educomunicação. Educomunicação, por sua vez, é a interface entre comunicação e educação (CITELLI e COSTA, 2011). Por meio dessa aproximação, busca-se compreender as formas de utilização das histórias em quadrinhos em sala de aula. Isso porque, de acordo com os mesmos autores, a educomunicação se preocupa com a produção, circulação e recepção didática de aparatos comunicacionais: “É possível conceber a 
educomunicação como uma área que busca pensar, pesquisar, trabalhar a educação formal, informal e não formal no interior do ecossistema comunicativo" (CITELLI e COSTA, 2011, p. 8).

O uso educomunicacional das histórias em quadrinhos em sala de aula não é, definitivamente, uma prática nova. Para exemplificar, basta acessarmos os livros produzidos no Brasil por Paulo Ramos (2009, 2017), Waldomiro Vergueiro (2009, 2010), Natália Nogueira (2017), Ângela Rama (2010), Fábio Paiva (2017a 2017b), Thiago Modenesi (2017), Elydio dos Santos Neto e Marta Regina Paulo da Silva (2013, 2014), além dos diversos artigos acadêmicos que proliferam em revistas qualificadas e a quantidade de comunicações em diferentes congressos de educação. Assim, 0 processo educomunicacional envolvendo histórias em quadrinhos já possui um campo consolidado de pesquisa, não apenas no Brasil mas também na comunidade científica internacional — como os trabalhos de Syma e Weiner (2013) ou Cary (2004).

Talvez o principal pilar do uso das histórias em quadrinhos em sala de aula seja o apontado por Santos (2016. O autor afirma que uma história em quadrinhos, seja uma tirinha ou uma história com mais de 200 páginas, não pode servir apenas como ilustração. Logo, se uma tira de histórias em quadrinhos no rodapé da página do livro didático está ali apenas como alívio cômico, ela não nos serve. Isso porque desejamos a problematização de algum tema por meio das histórias em quadrinhos. É interessante que os alunos possam refletir, por meio de uma ou mais histórias em quadrinhos, a respeito do tema proposto pelo professor. Ao inserir um exemplar da cultura de massa em sala de aula, o professor deve advertir os alunos que aquela história, naquele momento, não é para diversão. A história em quadrinho é material didático tão relevante quanto o livro didático ou o giz e o quadro negro (SANTOS, 2018).

Nesse sentido, a história aqui selecionada pode cumprir o papel de conscientizar e combater o coronavírus. Se bem problematizada, ela pode despertar nos alunos uma consciência importante neste momento de pandemia. 


\section{La Dansarina}

A história em quadrinhos La Dansarina foi escrita por Lillo Parra e desenhada por Jefferson Costa em 2015, em uma edição autoral — ou seja, sem editora. Dois anos mais tarde, a editora Jupati se interessou e relançou o material com maior e melhor distribuição, também com a finalidade de utilizá-lo na efeméride de 100 anos da gripe espanhola. Parra é paulistano e começou sua carreira como escritor de teatro. O autor iniciou sua carreira como roteirista de histórias em quadrinhos apenas em 2012, com o segundo volume da coleção Shakespeare Em Quadrinhos da editora Nemo (PARRA, 2020). O autor realizou inúmeras obras de histórias em quadrinhos, das quais podemos destacar Aventuras do Capitão Nemo, em 2013; Descobrindo um Novo Mundo, em 2015 e Frankenstein 200, em 2019. Jefferson Costa, por sua vez, é um artista gráfico muito prolífico e criador de diversas histórias em quadrinhos. $\mathrm{O}$ artista iniciou sua carreira profissional em 2003 e realizou diversas histórias em quadrinhos, entre elas A dama do Martinelli em 2012; Jeremias: Pele, em 2018 e Roseira, Medalha, Engenho e Outras Histórias em 2019 (COSTA, 2020).

A história em quadrinhos La Dansarina se passa em setembro de 1918 (PARRA e COSTA, 2017) em Salvador. Lá, uma bela espanhola desce de um navio e ao cumprimentar o estivador com a mão em seu queixo, deixa-o doente. O leitor então percebe que a personagem não é apenas uma espanhola; é a própria morte. A morte pela gripe espanhola. É interessante registrar que a denominação "gripe espanhola" é errônea. A praga provavelmente se originou nos Estados Unidos, nas péssimas condições de higiene dos campos de treinamento militares para a Primeira Guerra Mundial. A alcunha da doença com o nome do país latino veio, provavelmente, porque a Espanha era um país neutro durante a Guerra e, portanto, não censurou as notícias sobre a nova epidemia. (BERTUCCI-MARTINS, 2005).

A escolha do porto não foi aleatória pelos autores. Assim como na Covid-19 em 2020, essas doenças globais começam sua disseminação sempre em locais de trânsito internacional. A história tem uma elipse temporal e chega ao ano de 2010, onde um senhor de 104 anos está doente em um leito de hospital, sendo cuidado por seu neto (Santos, 2010). O tempo então retorna para 1918 e percebemos que este idoso agora tem apenas 12 anos de idade e está com gripe. Sua mãe recebe um pouco 
de remédio e deveria ter dividido com o garoto. Ela dá todo o conteúdo medicinal para o menino, que dorme por dias seguidos; entretanto, quando acorda, percebe a mãe morta.

O leitor então percebe que a história se passa em São Paulo. Cidade que, segundo com Bertucci-Martins (2005), havia muito sofrido com a pandemia em 1918. De acordo com a autora, foram inúmeras tentativas de conter a doença, desde o tratamento indicado de repouso e uso de quinino até tratamentos muito menos indicados, como o uso de "tônicos" miraculosos. Essas dinâmicas não muito diferentes do que foi visto no período mais crônico da pandemia de Covid-19; assim, elas podem ser problematizadas com os estudantes ao longo da atividade proposta — através da leitura da história em quadrinhos.

Outra característica que infelizmente se repetiu no Brasil em 1918 e em 2020 foram os cemitérios lotados. Sem possibilidade de enterrar a própria mãe, Pedro, o protagonista, aos 12 anos, decide enterrar sua mãe em outra cidade. Sem nenhum apoio governamental para o translado, o garoto decide fazer o transporte por si mesmo, tendo ajuda de um amigo da mãe que lhe empresta uma égua e uma padiola. Os autores da história em quadrinhos contam ao leitor, por intermédio de um personagem secundário, que não há mais bondes na cidade de São Paulo, pois os condutores estão todos doentes. O personagem conta, também, que não há mais médicos, pois os que ainda não estavam doentes fugiram para o interior, buscando um local com menos aglomeração. É interessante notar, e fazer com que os alunos percebam, que esta característica de transmissão das doenças foi a mesma, tanto em 1918 quanto em 2020; ou seja, em lugares com acúmulo de pessoas, como bondes, ônibus ou hospitais.

A partir daí, acompanhamos a trajetória de Pedro com sua mãe morta na padiola. A trama ganha ares de literatura fantástica e folclore - ao mostrar uma senhora benzedeira e um espírito que habita o corpo de um homem -, além de contar com elementos típicos da cultura brasileira, como o candomblé e a capoeira. Ao conseguir chegar à igreja de destino, o padre, já acamado por conta da gripe espanhola, revela ao menino que desde os tempos do imperador não se podia mais enterrar as pessoas na igreja, é necessário que isso seja feito em cemitérios. O garoto 
se desespera mas o padre informa que o menino pode enterrar sua mãe, desde que deixe muitas moedas sobre a cômoda.

No momento em que Pedro está cavando, a dançarina espanhola aparece e conversa com o menino; ele afirma conhecê-la e saber que ela é "La espanhola", "La Dansarina", "La muerte". Eles travam uma conversa amigável e a mulher revela que veio para levar o padre. O garoto diz que o padre não deixou que ele colocasse uma cruz para honrar sua mãe; a morte, então, faz nascer um broto de árvore, que em 2010 é a sombra na qual Pedro finalmente reencontra a dançarina espanhola que o leva.

\section{A gripe espanhola}

A doença conhecida como Gripe Espanhola, como já dissemos, não se propagou a partir do país ibérico. Ela se originou, provavelmente, nos EUA no final de 1917, durante a Primeira Guerra Mundial. A origem da doença está relacionada, principalmente, às péssimas condições de higiene do período (BERTUCCI-MARTINS, 2005). De acordo com Fioravanti (2020), esta moléstia infectou cerca de 500 milhões de pessoas pelo planeta, o que equivalia, aproximadamente, a um terço da população do mundo - matando entre 25 e 50 milhões de pessoas. Em São Paulo, cidade onde se passa a história relatada morreram pelo menos 5300 pessoas, cerca de $1 \%$ da população da cidade. Esse índice de $1 \%$ foi registrado também na maior cidade do Brasil no período, a capital Rio de Janeiro. No período mais agudo da epidemia, mortos se acumulavam nas ruas das duas cidades, e não havia cemitério ou pessoal para enterrar tanta gente.

A Gripe Espanhola foi produzida pelo vírus Influenza que normalmente atacava e matava os mais idosos, conhecidos pela fragilidade de seu sistema imunológico; assim, a doença era chamada de "limpa-velhos" no início do século XX (ALVES, 2020). Então, a primeira mudança sentida pela população de 1918 foi em relação ao alvo da doença. Os idosos não eram os mais atingidos e sim os jovens entre 20 e 40 anos, principais vítimas da doença. A segunda percepção em relação à enfermidade, veio após a já comentada infecção generalizada na população mundial; praticamente todo o planeta foi acometido pela doença. 
Para a maioria das pessoas, a doença era apenas um mal-estar que em cerca de uma semana já estava curado; porém, cerca de $1 \%$ de todas as pessoas que tinham contato com o vírus vinham a óbito. A doença, em seus casos mais leves, provocava febre que raramente passava dos $40^{\circ}$, catarro nasal, traqueobrônquico, prostração, dores de cabeça, sensação de mal-estar, entre outros sintomas menores. Já em seus casos mais graves, além do acima descrito, havia congestão pulmonar, complicações gastrointestinais e toxêmicas, congestão pneumônica e bronco pneumônica — além de deixar o coração debilitado (BERTUCCI-MARTINS, 2005).

Os principais remédios utilizados no período eram os derivados de quinino, substância que já tinha se mostrado eficiente contra a malária, grande mal que assolava o país nas décadas anteriores. Outras terapias envolviam

[...] repouso, pouca comida, cuidados com o bom funcionamento do aparelho digestivo, purgantes (com calomelano, sulfato de sódio ou magnésio, limonada purgativa etc.) e depois sudoríficos, em suas fórmulas científicas ou caseiras. Uma das receitas para provocar suores era: tintura de acônito, acetato de amônio, infusão de jaborandi, xarope de conhaque e de tília. Entre os chás, o de canela (BERTUCCI-MARTINS, 2005, p. 149).

Estas terapias mostravam-se eficazes na forma branda da doença, uma vez que, depois constatado, apenas repouso e hidratação já cumpririam o efeito desejado. Entretanto, tais remédios não funcionavam com as formas mais graves da doença, que se mostraram incuráveis.

\section{Covid-19}

A doença conhecida como Covid-19 teve seu anúncio feito pela Organização Mundial de Saúde no final de 2019. Nos cinco meses subsequentes, 188 outros países foram afetados pela doença, sendo declarada pandemia em abril de 2020 . O início da propagação da doença se deu na cidade chinesa de Wuhan, na província de Hubei, na China. (SOUTO, 2020).

Assim como na Gripe Espanhola, a taxa de morte da doença é relativamente baixa, em torno de 1\%. Entretanto, sua taxa de contágio é talvez uma das mais altas já vistas pelos seres humanos, agindo em forma exponencial (ORNELL, SCHUCH, et 
al., 2020), o que acarreta inúmeros problemas tanto sociais quanto psicológicos. Os autores chegam a afirmar em seu artigo que o número de pessoas cuja saúde mental é afetada tende a ser maior do que o número de pessoas afetadas pela infecção.

O novo coronavírus (também chamado SARS-CoV-2), produtor da COVID-19, se espalha facilmente e de maneira sustentada entre a população, principalmente por meio do spray de gotículas produzido durante a fala, tosses e espirros. Souto (2020) fala que a transmissão pelo indivíduo infectado se realiza normalmente nos primeiros três dias após o início dos sintomas. Entretanto, não se pode ignorar que alguns indivíduos transmitem a doença antes de apresentar os sintomas, e que algumas pessoas apesar de não apresentarem sintomas, possuem o vírus no corpo e podem transmitir também por meio de gotículas. Ainda de acordo com a autora, o período de incubação da doença é entre dois e quatorze dias, o que deixa a população mais vulnerável, uma vez que o sujeito contaminado não sabe de sua condição e contamina muitas pessoas até os sintomas efetivamente aparecerem.

Os sintomas são diversos, alterando de pessoa para pessoa (CDC, 2020), mas os mais comuns são febre alta, falta de ar e tosse seca. Em boa parte dos casos não é preciso muita interferência medicamentosa, tratando apenas os sintomas. Entretanto, tal qual a pandemia de 1918, uma parcela da população será atingida mais duramente pela infecção, e neste caso, ainda de acordo com o CDC (2020), podem desenvolver pneumonia, insuficiência respiratória hipoxêmica e choque séptico. Nesses casos mais graves, os pacientes normalmente são internados. Alguns precisam ir para a Unidade de Tratamento Intensivo e outros ainda precisam de ventilação artificial, ou seja, respirar por meio de um pulmão artificial.

Ainda que pessoas e empresas tentem difundir curas "miraculosas" e “certeiras" - assim como em 1918 — até o momento da escrita deste artigo, não foi achado nem um tratamento, tampouco uma vacina para a profilaxia. Assim, as principais medidas adotadas são a de distanciamento social, ou seja, manter-se afastado pelo menos um metro das pessoas próximas, o uso de máscaras e o isolamento de pessoas sabidamente infectadas. Todas essas medidas, de acordo com a Organização Mundial da Saúde (OMS), como formas de manter as gotículas possivelmente infectadas longe do contato com pessoas saudáveis (OMS, 2020). Mais do que isso, a mesma entidade avisa à população para lavar as mãos com água 
e sabão tantas vezes quanto puder, e, se não puder, utilizar álcool 70\%, notadamente em sua versão em gel, mais prática e portátil. Diz ainda o comunicado da Organização Mundial da Saúde para as pessoas evitarem aglomerações, concertos de música, shopping centers ou qualquer outro local com distância mínima de um metro. Graças ao suor das mãos, recomenda-se não haver cumprimento com as mãos e menos ainda com beijos no rosto ou nos lábios. É importante também não levar a mão aos olhos, boca ou nariz, principais entradas do vírus no organismo. E, como principal forma de prevenção, se informar em fontes confiáveis, uma vez que vivemos uma época em que notícias falsas são colocadas na internet e muitas pessoas infelizmente acreditam (OMS, 2020).

\section{Usando La Dansarina em sala de aula}

Novamente, de acordo com Santos (2016), é importante que o professor saiba que a primeira coisa que deve fazer ao levar um material para sala de aula é garantir a reprodutibilidade dele. E, claro, garantir que os alunos leram o material. Por se tratar de uma história em quadrinhos de 120 páginas, o tempo de leitura deve ser alinhado de acordo com o público que será encontrado. Um estudante do Ensino Médio, por exemplo, levará em torno de 60 a 90 a minutos para ter a leitura completa. São algumas as alternativas para esta leitura. A mais interessante seria que cada aluno tivesse uma cópia do livro em questão, o que nos parece inviável. O álbum atualmente custa cerca de $\mathrm{R} \$ 50,00$ e em uma sala com 40 alunos daria $\mathrm{R} \$ 2000,00$. Entretanto, caso a escola tenha uma verba na biblioteca, poderia comprar uns 10 exemplares que, emprestados em forma de rodízio, daria facilmente para toda a turma. Caso essa possibilidade também não se mostre viável, o professor pode escanear a obra e apresentá-la com o auxílio de um equipamento de projeção na sala de aula. "Caso a escola não tenha projetor, o docente pode também disponibilizar estas fotos com a história em um serviço de armazenamento de fotos ou um blog gratuitamente, desde que apague tais fotos após o uso, para não ser caracterizado cópia pirata." (SANTOS, 2018, p. 371). Pode o docente também expor apenas as partes mais importantes da história aos alunos, mas não aconselhamos, pois essa visão fragmentada da obra pode não ser tão atrativa aos alunos. 
Uma vez resolvida a questão da leitura dos alunos, passaremos a apresentar algumas tentativas que podem ser úteis aos professores quando forem tratar do tema, mas sempre levando em consideração, como faz Santos (2016), que cada turma é singular, e que o professor pode adaptar cada uma das ideias aqui apresentadas para sua turma específica, afinal, ninguém entende melhor seus alunos do que o próprio docente.

A primeira das problematizações que podemos fazer diz respeito à incapacidade ou dificuldade da população em aprender com a pandemia passada. Analisando a epidemia da Gripe Espanhola, sabemos que a melhor maneira de conter a pandemia é o isolamento social, tal como propaga a OMS (2020) e é mostrado na cena em que Pedro vai passar por um vilarejo e as pessoas o expulsam, pois ele "deve di tá cum a hespanhola tamém" (PARRA e COSTA, 2017, p. 33). As pessoas, em 1918, sabiam que a transmissão era feita de pessoa para pessoa. Além disso, estavam acostumadas ao infortúnio das "pestes" (BRITO, 1997). Não podemos aqui esquecer o que Delumeau (1989) deixou claro ao declarar que entre 1348 e 1720, a Europa se viu em constantes pestes, que chegavam a dizimar metade da população em determinadas localizações. Além disso, a doença conhecida como Cólera havia surgido menos de um século antes, provavelmente por volta de 1830.

As pestes (tais como a bubônica ou a lepra) compelem os indivíduos a romperem seus laços de comunicação tanto com familiares quanto com amigos. Em 1918 o que podiam fazer era se resguardar em casa e, restabelecida a normalidade, voltar ao convívio dos familiares que haviam sobrevivido, como diz a madrinha de Pedro, na página 30 da história: “quando termina, volta direto prá cá! Tá ouvino?” (PARRA e COSTA, 2017, p. 30). Em 2020, tal procedimento não é necessário para boa parte da população, haja vista que ferramentas de comunicação como telefones celulares, internet e computadores estão relativamente acessíveis para grande parte da sociedade.

Esta profusão de equipamentos de comunicação, porém, tem seu lado nefasto. Como as comunicações passaram a ser mais descentralizadas com o advento da internet, qualquer pessoa pode explanar suas ideias. E nem sempre elas são as mais corretas. Há, portanto, uma imensidão de notícias falsas, remédios caseiros ineficientes ou tratamentos sem qualquer comprovação científica que ficam 
circulando pelos smartphones das pessoas, em 2020. Isso também tem uma contraparte na pandemia de pouco mais de cem anos, em que, de acordo com Bertucci-Martins (2005), diversas empresas começaram a fabricar elixires ou tônicos sem qualquer comprovação, mas que eram vendidos para as pessoas como cura da doença. Como já afirmamos, o quinino parecia ser o componente mais desejado pelas pessoas de então, mas que comprovadamente não surtia nenhum efeito nas vítimas mais sérias da doença. Isso já no início da trama, quando a mãe de Pedro recebe do farmacêutico um pacote com "quinino, menta canforada e umas aspirina." (PARRA e COSTA, 2017, p. 14). O quinino não salvou a mãe de Pedro e, provavelmente, também não foi o que o salvou. O docente pode pegar este trecho e discutir com os alunos sobre tratamentos, eficácia e a relação entre a ciência e as comunicações mal feitas.

Outra análise que o professor pode fazer com seus alunos diz respeito ao discurso dos políticos em meio à pandemia. Uma característica em comum de ambas as doenças é que os governos brasileiros zombaram dela em princípio. O presidente Jair Bolsonaro, em 2020, disse se tratar de uma "gripezinha", e que não havia com o que se preocupar. Em 1918, Rodrigues Alves, então presidente do Brasil, diz a mesma coisa, que não era necessária preocupação. Na história em quadrinhos, o presidente de 1918 é levado pela Dansarina, que lhe pergunta quantos mais terão de morrer até que ele tome uma providência. Na ficção de Parra e Costa ele começa a tossir. Na vida real, o presidente Rodrigues Alves morreu em 16 de janeiro de 1919, vítima da Gripe Espanhola.

Parece haver uma necessidade governamental de negar a ferocidade da doença e, assim, tentar manter a sociedade em movimento, principalmente por conta do comércio, do capitalismo, que não consegue sobreviver sem a presença de pessoas nas ruas, nas lojas. Com isso, ambos os governos, separados por pouco mais de cem anos, cometem o mesmo erro de minimizar a enfermidade e, com isso, serem responsabilizados pela imprensa e pela população de forma geral pelas mortes ocorridas no período. Analisar os discursos dos mandatários da nação em ambas as crises pode ser muito interessante para a discussão com os alunos em relação ao papel do Estado, o papel da sociedade e o papel do indivíduo em momentos críticos como estes. 
Estas são apenas algumas possibilidades para o uso desta obra em sala de aula com o foco na comparação entre as duas pandemias e a busca por uma maior conscientização dos alunos a respeito da Covid-19. Acreditamos que, ao conhecer a maneira como uma doença anterior se comportou em nosso país, os estudantes podem prestar mais atenção em suas atitudes, e as pequenas ações como as de higiene e distanciamento social fiquem mais comuns, promovendo um ambiente mais saudável para todos.

Como percebemos, a maior arma que temos contra o vírus é a disseminação da informação e a mudança de hábitos da população. Isso ficou evidente no surto em 1918 e esperamos que a leitura de uma obra ficcional com um pano de fundo tão complexo ajude os jovens a se conscientizarem de seu papel cidadão. É interessante lembrar aos alunos - especialmente aos mais jovens - que por mais que os mais novos não desenvolvam a doença de forma tão grave, eles podem ser os vetores que vão levar seus parentes mais idosos à morte. Na história aqui apresentada, Pedro vê sua mãe falecer. As crianças, em 1918, eram muito pouco suscetíveis à morte pela Gripe Espanhola, mas os adultos entre 20 e 40 anos, como vimos, eram as principais vítimas. O professor pode tentar conscientizar os alunos da gravidade da doença simplesmente apontando para o fato de que um menino de 12 anos teve que enterrar sua própria mãe. E ainda que naquele momento não tenha sido culpa do garoto, em 2020 pode ser que o aluno seja o vetor que vai trazer a doença para o seio do seu lar.

\section{CONSIDERAÇÕES FINAIS}

Ao final deste artigo, podemos considerar que a disseminação da informação em sala de aula pode ser a maior arma contra uma doença que se espalha pelo convívio social e para a qual não existe ainda uma vacina ou tratamento eficiente. Com estudantes bem informados, existe uma chance maior de que eles acatem as decisões de distanciamento social tão importantes para a solução de uma crise sanitária, bem como passem adiante tais informações.

O uso das histórias em quadrinhos, neste contexto, é interessante pois sua utilização de forma lúdica pode trazer uma motivação maior para o aprendizado. E, neste caso específico, a obra de Parra e Costa parece-nos adequada pois traz uma 
doença muito similar em sua forma de contágio e que afetou sobremaneira o Brasil há cerca de um século atrás.

O professor, mostrando os acertos e os erros feitos no período de 1918, pode apresentar aos seus alunos os caminhos pelos quais a trilha será menos danosa e, tão importante quanto, instigar neles a necessidade de se seguir as recomendações das autoridades sanitárias, da ciência.

A comparação entre os dois governos separados por pouco mais de cem anos também pode ser de extrema valia para o entendimento social e político da crise gerada por uma pandemia como esta, e descortinar atitudes de autoridades que estão mais preocupados com a saúde da economia do que com a saúde da população.

Por último, a tensão emocional da obra também pode ser muito útil para o professor passar o senso de urgência de uma calamidade pública. Assistir nos telejornais ou ouvir na rádio o número de mortos diariamente pode trazer um certo distanciamento com o problema, afinal, são apenas números. Mas o docente, ao mostrar uma história na qual um menino tem que lutar para enterrar a própria mãe pode trazer um senso de unidade, uma perspectiva de intimidade com o problema. Não são dez ou cem mil mortos. É a mãe de um garoto.

\section{REFERÊNCIAS}

ALVES, G. W. Uma comparação entre a pandemia de Gripe Espanhola e a pandemia de Coronavírus. UFRGS, 17 abr. 2020. Disponível em: https://www.ufrgs.br/coronavirus/base/uma-comparacao-entre-a-pandemia-degripe-espanhola-e-a-pandemia-de-coronavirus/. Acesso em: 29 jun. 2020.

BERTUCCI-MARTINS, L. M. Entre doutores e para os leigos: Fragmentos do discurso médico na influenza de 1918. História, Ciências, Saúde, Rio de Janeiro, v. 12, n. 1, p. 143-157, jan-abr. 2005. Disponível em: https://www.scielo.br/pdf/hcsm/v12n1/07.pdf.

BRITO, N. A. D. La Dansarina: a gripe espanhola e o cotidiano na cidade do Rio de Janeiro. História, Ciências, Saúde, v. 4, n. 1, p. 11-30, mar-jun 1997.

BRUNER, J. S. Sobre o Conhecimento: Ensaios da mão esquerda. São Paulo: Phorte, 2008.

CARY, S. Going Graphic: Comics at work in the multilingual classroom. EUA:

Heinemann Press, 2004. 
CDC. Coronavirus Disease 2019 (COVID-19): Symptoms of Coronavirus. CDC, 2020. Disponível em: https://www.cdc.gov/coronavirus/2019-ncov/symptomstesting/. Acesso em: 30 jun. 2020.

CITELLI, A. O.; COSTA, M. C. C. Introdução. In: CITELLI, A. O.; COSTA, M. C. C. Educomunicação: Construindo uma nova área do conhecimento. São Paulo: Paulinas, 2011.

COSTA, J. Blog do Jefferson Costa, 2020. Disponível em: http://jeffersoncostablog.blogspot.com/. Acesso em: 29 jun. 2020.

DELUMEAU, J. História do medo no Ocidente (1300-1800). São Paulo: Companhia das Letras, 1989.

EISNER, W. Quadrinhos e Arte Sequêncial. São Paulo: Martins Fontes, 2010.

FIOCRUZ. Perguntas e Respostas. Fiocruz, 25 jun. 2020. Disponível em:

https://portal.fiocruz.br/pergunta/por-que-doenca-causada-pelo-novo-virus-recebeuo-nome-de-covid-19.

FIORAVANTI, C. Pesquisa Fapesp, 2020. Disponível em:

https://revistapesquisa.fapesp.br/semelhancas-entre-a-gripe-espanhola-e-a-covid19/. Acesso em: 29 jun. 2020.

GORDON, I. Comic Strips and consumer culture. EUA: Smithsonian Institution Press, 1988.

GROENSTEEN, T. O sistema dos Quadrinhos. Nova Iguaçú: Marsupial, 2015.

JUNIOR, G. A Guerra dos Gibis. São Paulo: Companhia das Letras, 2004.

MODENESI, T. Educação para abolição: Charges e Histórias em Quadrinhos no Segundo Reinado do Brasil. Recife: Tarcísio Pereira Editor, 2017.

NETO, E. D. S.; SILVA, M. R. P. D. Histórias em quadrinhos e práticas educativas. 0 trabalho com universos ficcionais e fanzines. São Paulo: Criativo, 2013.

NETO, E. D. S.; SILVA, M. R. P. D. Histórias em quadrinhos e práticas educativas: Os gibis estão na escola, e agora? São Paulo: Criativo, 2014.

NOGUEIRA, N. As histórias em quadrinhos e a escola. Leopoldina: Aspas, 2017.

OMS. Aviso ao público. Organização Mundial da Saúde, 2020. Disponível em: https://www.who.int/emergencies/diseases/novel-coronavirus-2019/advice-forpublic. Acesso em: 30 jun. 2020.

ORNELL, F. et al. "Pandemic fear" and Covid-19: Mental health burden and strategies. Brazilian Journal of Psychiatry, 2020.

PAIVA, F. Histórias em quadrinhos na educação. Recife: Quadro a quadro, 2017.

PARRA, L.; COSTA, J. La Dansarina. Nova Iguaçu: Jupati, 2017. 
PARRA, L. Site Oficial. Lillo Parra - Site Oficial, 2020. Disponível em: http://lilloparra.com.br/. Acesso em: 29 jun. 2020.

RAMA, Â.; VERGUEIRO, W. Como usar as histórias em quadrinhos na sala de aula. São Paulo: Contexto, 2010.

RAMOS, P. Tiras no ensino. São Paulo: Parábola, 2017.

RAMOS, P.; VERGUEIRO, W. Quadrinhos na educação. São Paulo: Contexto, 2009.

SANTOS, R. O. D. Webcomics Malvados: Tecnologia e Interação nos quadrinhos de André Dahmer. 2010. Dissertação ( Mestrado em Tecnologia )- Programa de Pósgraduação em Tecnologia, UTFPR, Curitiba, p. 259, 2010. Disponível em: http://repositorio.utfpr.edu.br/jspui/handle/1/179.

SANTOS, R. O. D. Fundamentos da Pesquisa Histórica. Curitiba: Intersaberes, 2016.

SANTOS, R. O. D. Algumas possibilidades das histórias em quadrinhos como recursos de prática docente na área de História na Educação Básica. AEDOS, v. 10, n. 23, p. 354-373, 2018. Disponível em:

https://www.seer.ufrgs.br/aedos/article/view/85132/52136.

SOUTO, X. M. COVID-19: ASPECTOS GERAIS E IMPLICAÇÕES GLOBAIS. Recital: Revista de Educação, Ciência e Tecnologia de Almenara/MG, Almenara, v. 2, n. 1, p. 12-36, abril 2020.

SYMA, C. K.; WEINER, R. Graphic Novels and comics in the classroom: essays on the educational power of sequential art. Jefferson: McFarland Press, 2013.

VERGUEIRO, W. O Tico-tico 100 anos. São Paulo: Ópera Graphica, 2005. 